\title{
Macroprudential Policy under Incomplete Information
}

\author{
Margarita Rubio* \\ D. Filiz Unsal ${ }^{\dagger}$ \\ University of Nottingham \\ International Monetary Fund
}

September 2019

\begin{abstract}
In this paper, we use a DSGE model to study the passive and time-varying implementation of macroprudential policy when policy-makers have noisy and lagged data. The model features an economy with two agents; households and entrepreneurs. Entrepreneurs are the borrowers in this economy and need capital as collateral to obtain loans. The macroprudential regulator uses the collateral requirement as the policy instrument. In this set-up, we compare policy performances of permanently increasing the collateral requirement (passive policy) versus a time-varying (active) policy which responds to credit developments. Results show that with perfect and timely information, an active approach is welfare superior, since it is more effective in providing financial stability with no long-run output cost. If the policy-maker is not able to observe the economic conditions perfectly or observe with a lag, a cautious (less aggressive) policy or even a passive approach may be preferred. However, the latter comes at the expense of increasing inequality and a long-run output cost, which could outweigh their macroeconomic and financial stability benefits.
\end{abstract}

Keywords: Macroprudential policy, incomplete information, collateral requirements, credit, inequality.

JEL Classification: E44; E32; G18

${ }^{*}$ University of Nottingham, School of Economics. Sir Clive Granger Building, University Park, Nottingham, NG7 2RD, UK. E-mail: margarita.rubio@nottingham.ac.uk.

${ }^{\dagger}$ International Monetary Fund. Research Department. 700 19th Street, N.W., Washington DC, 20431. E-mail: DUnsal@imf.org. 


\section{Introduction}

The recent financial crisis has emphasized that there is the need for policies that enhance the stability of the overall financial system, namely macroprudential policies. However, the policy agenda is still very much evolving and there is scarce evidence on the implementation of these policies around the globe.

There are several ways macroprudential instruments could be designed and implemented, with important implications for the financial system and the overall economy. At least, it has to be taken into account that macroprudential policy has both benefits as well as costs. The benefits, when tools are used effectively, include a more stable financial system, which in principle reduces the probability of a crisis and its impact when/if it happens. However, these tools could have other economic implications as they could restrict credit and financial access more broadly; and could bring short and long-run output costs. $^{1}$

One plausible approximation of a macroprudential policy implementation is time-varying rules that tie policy settings to a pre-defined indicator. This approach is similar to a Taylor rule for monetary policy. In theory, it is useful to vary macroprudential instruments over the cycle - it does not imply any long-run output cost, it could help to overcome political pressures on the policy moves and timeinconsistency problems. An alternative option would be a passive policy in which instruments tighten borrowing requirements permanently.

Global thinking and practice seem to favor time-varying rules on instruments such as loan-to-values or capital requirement ratios. However, for some countries, this may not be the case. As Gottschalk (2014) points out, international financial regulation has been designed having in mind developed and emerging countries and includes some complex rules that some countries have difficulties in following. ${ }^{2}$ There are countries, for instance low-income and developing (LIDCs), in which the combination of limited data availability, volatile economic conditions, and weak supervisory capacity can mean that a passive policy can be preferred, an active and time-varying use of macroprudential policy may be inadvisable. ${ }^{3}$ Maintaining permanently high capital or collateral requirements could be a more effective approach under

\footnotetext{
${ }^{1}$ See Arregui (2013).

${ }^{2}$ According to Gottschalk (2014), some of these countries seemed to feel that adoption of these complex rules was a way to signal they were adopting standards of international best practice, even if they were not the most appropriate to meet their needs (See Beck et al., 2013, chapter 5). Nevertheless, complexity of policies is a relevant issue for LIDCs given their limited technical capacity to validate and monitor complex models, and the lack of sufficiently large and reliable databases. Gottschalk (2014) argues that countries have eventually realized that the rules were not appropriate to them and prefer simpler alternatives.

${ }^{3}$ While the LIDCs are a diverse group of countries, they share characteristics common to all countries at a low level of development. According to the IMF definition (IMF, 2014a), there are 60 countries in this group, accounting for about one-fifth of the world population; Sub-Saharan Africa accounts about 60 percent of the LIDC population.
} 
these circumstances (IMF, 2014b). Nevertheless, these type of policies may bring dramatic output effects through affecting the cost and availability of credit. Such policies may also favor more well-off segments of the population and enhance inequality, which can undermine progress in health and education, cause investment-reducing political and economic instability (IMF, 2014c).

Monetary policy implementation when there is incomplete information is an issue that has been widely studied. However, the literature is silent on how limited data availability may affect the implementation of macroprudential policy.

In this paper, we use a DSGE model with capital collateral for borrowing and high collateral requirements to address the problem of incomplete information when implementing macroprudential policy. We focus on how macroprudential policy design should take into account data and capacity limitations. As in the monetary policy literature, we proxy these data problems with the absence of complete information (without noise and lag). The model features two types of agents; households and entrepreneurs. Entrepreneurs can access financial markets as long as they own capital collateral. Macroprudential policy is represented by changes in the collateral requirement. We compare a passive macroprudential policy, in which collateral requirements are increased permanently; with an active policy, in which the collateral requirements respond to deviations of credit with respect to its steady state. For our comparison, we consider two scenarios: (i) macroprudential policy-makers have complete information, (ii) macroprudential policy-makers have incomplete information in which financial indicators are not observed with accuracy and in a timely manner.

In order to evaluate policies we adopt a positive approach complemented with welfare analysis. As in Angelini et al. (2014), among others, we take regulation as given and calculate welfare values under this assumption to compare different ways of implementing macroprudential policy.

This paper relates to different strands of the literature. On the one hand, it is builds from DSGE models with collateral constraints such as Kiyotaki and Moore (1997), Iacoviello (2005) or Iacoviello and Minetti (2006). However, in our paper, unlike the others, the main source of collateral is capital, which is a more general source of collateral than housing and can be extended to a wider range of countries, including LIDCs. ${ }^{4}$ This paper is also related with the literature that studies macroprudential policies in a DSGE model, introducing such policies as a rule on financial regulation. Examples of these papers are Kannan et al. (2012), Unsal (2013), Angelini et al. (2014) and Rubio and Carrasco-Gallego (2014).

\footnotetext{
${ }^{4}$ The main source of macro-financial fragility in advanced and emerging economies has generally been housing booms. In LDICs, however, mortgage markets are still underdeveloped.
} 
However, all these papers refer to macroprudential policy when there is complete information. Those papers use capital requirements or loan-to-values as macroprudential instruments. In our paper, the instrument is the collateral requirement, which is the mirror image of the loan-to-value ratio and has a great importance in countries in which the incomplete information problem is an important issue. Our study, thus, adds incomplete information in the specification of the macroprudential rule, as in the literature on monetary policy rules with incomplete information. This is the most important innovation of our paper, borrowing the idea of incomplete information for monetary policy to the macroprudential policy case. For instance, Berg et al. (2010) and Portillo et al. (2016) study monetary policy responses under incomplete information for LIDCs. ${ }^{5}$ These authors, like us, acknowledge that data problems are an important feature in LIDCs. We extend these idea to macroprudential policy implementation although we do not confine the results to this group of countries. In the broader monetary policy literature, incomplete information has been thoroughly analyzed. For instance, Aoki (2003) or Orphanides (2003) analyze optimal monetary policy with noisy indicators. These papers find that when the monetary policy-maker uses simple rules with incomplete information, the outcome can be more price instability. Our results are analogous to the monetary policy literature. We find in our paper that, macroprudential rules under incomplete information may deliver financial instability. This issue has also been studied in more recent papers for monetary policy because data limitations are a persistent problem in many countries. Gust et al. (2015), for example, focus on the imperfect knowledge of the natural rate of interest when making monetary policy decisions, based on a simple Taylor rule. As in our paper, these authors also compare between different ways to implement the rule and look at simpler approaches as alternatives when this problem is present in the economy. Taylor and Williams (2010) also touch upon the issue that many macroeconomic data series such as GDP and price deflators are subject to measurement errors and revisions, and this affects the performance of the monetary policy rule. In our paper, analogously, we consider that financial data series also suffer from such problems and this affects the macroprudential rule. Boehm and House (2014) study optimal Taylor rules when the inflation and the output gap terms are observed with an error. They find that the policy-maker should fight more strongly against inflation to compensate for this data issue. Unlike their paper, we find that, for macroprudential rules, when there is incomplete information, fighting aggressively against deviations of credit from it steady state, may worsen the problem. Our finding is related to a general result in this literature that shows that the

\footnotetext{
${ }^{5}$ There are several other papers that incorporate specific features of LIDCs in a DSGE setting. See Baldini et al. (2015) and Dabla-Norris et al. (2015), for example. These papers are however silent on how macroprudential policies should be implemented in such countries.
} 
optimal coefficient on the output gap in the policy rule declines in the presence of errors in measuring the output gap. The logic behind this result is similar to ours; the response to the mismeasured output (or to the credit gap in our case) adds unwanted noise to the setting of policy which can be reduced by lowering the coefficient on the gap in the rule.

To our knowledge, our paper is the first one that studies alternative ways of implementing macroprudential policy under the presence of incomplete information. This is a relevant problem in LIDCs although it can also be applicable to some emerging and advanced economies, in the same way as its counterpart for the monetary policy literature. Therefore, we try to make our model as general as possible, to take into account all these countries. Thus, although we incorporate some LIDCs features in the model and the discussion, those are not confined to them. ${ }^{6}$ This paper permits to analyze different policy options within a rigorous micro-founded model, suitable for policy evaluation. It provides a theoretical counterpart to empirical studies and policy papers that point out that the particular feature of incomplete information in data may alter the desirable and effective way to implement macroprudential policy. It also complements the monetary policy literature on incomplete information by extending this idea to macroprudential policy implementation.

We also touch upon the effects of these policies on inequality, a relatively unexplored topic in the context of macroprudential policy. In many of the countries that feature the problem of noisy data, improving inequality remains as one of the most important macroeconomic policy objectives and policymakers generally attach considerable weight to distributional consequences of policies. By providing some insights on the inequality implications of macroprudential measures, we aim to bring a more complete picture on the issue for these countries. ${ }^{7}$

Results show that macroprudential tools are effective in improving financial stability by lowering the volatility of credit. If the macroprudential policy-maker is able to observe economic indicators (complete information case), active time-varying policies are preferred to passive approaches. Active policies, being countercyclical, are more effective to achieve financial stability without incurring in any long-run output

\footnotetext{
${ }^{6}$ The model does not have to be taken as a model for LIDCs. We acknowledge that, if the model were specific for those countries, there would be other issues relevant to LIDCs to be included - such as low financial deepening, commodity exporters, low capacity, informality in the access to finance, limited financial access, high exposure of the banking system to the government and weak policy frameworks for monetary and fiscal policy - that could have an impact on how macroprudential policies should be designed and implemented.

${ }^{7}$ Several recent studies analyze inequality implications of various policies and shocks in a heterogenous agents setting which may allow the interaction of availability/cost of credit with occupational choice and/or firm entry. Dabla-Norris et al. (2015), for example, find that lower collateral contsraints bring sizeable inequality gains as some of the high productivity/ lower income households become entrepreneurs and increase their income. As we use a representative agents model, these important channels are shut down.
} 
cost. Passive policies, although they also enhance a more stable financial system, they are not as effective and they imply a permanently lower steady-state output. However, if policy-makers observe the economic data with a lag and with some noise (incomplete information case), this may not be the case. Under

these circumstances, a more cautious (less aggressive) response or even a passive approach may be more advisable even though the latter entails an output cost. Nevertheless, this cost is not evenly distributed among agents and inequality increases. Welfare values are in line with these results.

The policy implications of these results are clear-there should be an effort in these countries to improve data and capacity issues to better monitor financial systems and to develop time-varying approaches which do not imply long-run output or inequality costs. In the meantime, a less aggressive response to financial sector developments could be desirable.

The rest of the paper continues as follows. Section 2 presents the basic model. Section 3 shows the dynamic properties of the model. Section 4 describes the macroeconomic and financial effects of macroprudential policy. Section 5 describes how alternative implementation of this policy affects inequality. Section 6 presents welfare results. Section 7 provides a policy comparison. Section 8 concludes.

\section{The Model}

We consider an infinite-horizon economy. The economy is populated by infinitely lived agents, entrepreneurs (borrowers) and households (savers). There are capital producers that sell the capital goods output to entrepreneurs. Households rent labor to entrepreneurs and consume the final good; they also trade non-contingent one-period bonds issued by entrepreneurs. Entrepreneurs consume and use labor and capital to produce the final good; and use capital as collateral to access financial markets. The macroprudential instrument is the collateral requirement.

\subsection{Entrepreneurs/Firms}

Entrepreneurs produce the final consumption good according to a Cobb-Douglas production function in domestically located labor $l_{t}$ and capital $k_{t}$, which depreciates at rate $\delta$ over time:

$$
Y_{t}=k_{t}^{\mu} l_{t}^{1-\mu}
$$

Entrepreneurs maximize their lifetime utility from the consumption flow $c_{t}$. We denote with $E_{t}$ the expectation operator conditional on time $t$ information and with $\gamma$ the entrepreneurs' discount factor. 
Entrepreneurs solve the following problem:

$$
\max _{c_{t}, b_{t}, l_{t}, k_{t+1}} E_{0} \sum_{t=0}^{\infty} \gamma^{t} \ln c_{t}
$$

subject to the flow of funds:

$$
k_{t}^{\mu} l_{t}^{1-\mu}+b_{t}+q_{t}(1-\delta) k_{t}=c_{t}+q_{t} k_{t+1}+R_{t-1} b_{t-1}+w_{t} l_{t}
$$

where $\gamma$ is the entrepreneurial discount factor, $b_{t}$ represents borrowing of the entrepreneur, $R_{t}$ is the gross interest rate, $q_{t}$ is the price of capital and $w_{t}$ is the real wage. ${ }^{8}$

Assuming that $k$ is collateralizable, we denote $z$ the value of capital collateral required to obtain one unit of loans. Then, the entrepreneur faces the following borrowing constraint: ${ }^{9}$

$$
b_{t} \leq \frac{1}{z_{t}} \frac{q_{t} k_{t+1}}{R_{t}}
$$

This collateral constraint is analogous to the ones used in Kiyotaki and Moore (1997) or Iacoviello (2005) but using capital instead of land and housing as collateral, which is a more general source of collateral and makes the model applicable also to countries in which housing markets are underdeveloped.

Entrepreneurs choose labor and capital and how much to borrow from households; The first-order conditions are as follows:

$$
\begin{gathered}
\frac{1}{c_{t}}=E_{t}\left(\frac{\gamma R_{t}}{c_{t+1}}\right)+\lambda_{t} R_{t} \\
w_{t} l_{t}=(1-\mu) y_{t} \\
\frac{1}{c_{t}} q_{t}=E_{t} \frac{\gamma}{c_{t+1}}\left(\mu \frac{y_{t+1}}{k_{t+1}}+q_{t+1}(1-\delta)\right)+\lambda_{t} q_{t} \frac{1}{z_{t}}
\end{gathered}
$$

where $\lambda_{t}$ is the Lagrange multiplier of the borrowing constraint. The first-order conditions are the consumption Euler equation (4), labor demand (5), and capital demand (6). The consumption Euler

\footnotetext{
${ }^{8}$ Entrepreneurs are perfectly competitive.

${ }^{9}$ Entrepreneurs are also goods producers and capital is a factor of production, this is why capital is an asset for them. Then, the fact that $k$ is collateralizable implicitly shows up in the term $b_{t}$, which is related to the collateral constraint so $\frac{1}{z}$ enters the equation implicitly through $b_{t}$.
} 
equation and the capital demand differ from the usual formulations because of the presence of the Lagrange multiplier on the borrowing constraint.

\subsection{Households}

We denote households' variables with a prime. Households enter each period with a bond coming to maturity. They derive utility from consumption and leisure. ${ }^{10}$ They rent labor to the entrepreneur, lend $b_{t}$, while receiving back the amount lent in the previous period times the agreed gross interest rate $R$.

Preferences are given by:

$$
\max _{c_{t}^{\prime}, b_{t}^{\prime}, l_{t}} E_{0} \sum_{t=0}^{\infty} \beta^{t}\left(\ln c_{t}^{\prime}-\frac{1}{\eta} l_{t}^{\eta}\right)
$$

where $\beta$ is the discount factor, which is assumed to be greater than $\gamma$, the discount factor for entrepreneurs. ${ }^{11}$

Households maximize (7) subject to the flow of funds:

$$
c_{t}^{\prime}+b_{t}^{\prime}=R_{t-1} b_{t-1}^{\prime}+w_{t} l_{t}
$$

Solution of this problem yields the following first-order conditions:

$$
\begin{gathered}
\frac{1}{c_{t}^{\prime}}=\beta E_{t}\left(\frac{R_{t}}{c_{t+1}^{\prime}}\right) \\
w_{t}=c_{t}^{\prime} l_{t}^{\eta-1}
\end{gathered}
$$

where equation (9) represents the Euler equation for consumption. Equation (10) is the labor supply schedule.

\subsection{Capital Producers}

Competitive capital producers use investment as materials input $i_{t}$ and produce new capital goods sold at price $q_{t}$. We assume that the marginal return to investment in terms of capital goods is decreasing in

\footnotetext{
${ }^{10}$ Notice that entrepreneurs derive utility only from consumption because they do not work.

${ }^{11}$ In a neighborhood of the steady state equilibrium, the multiplier associated with the entrepreneurs collateral constraint is positive, as long as the entrepreneurial discount factor $\gamma$ is lower than the households'discount factor $\beta$, which in turn prices bonds.
} 
the amount of investment undertaken due to the presence of adjustment costs.

The representative firm solves:

$$
\max _{i_{t}} q_{t}\left[\left(\frac{i_{t}}{k_{t}}\right)-\frac{\phi}{2}\left(\frac{i_{t}}{k_{t}}-\delta\right)^{2}\right] k_{t}-i_{t}
$$

The first order condition for $i_{t}$ is as follows:

$$
q_{t}=\left[1-\phi\left(\frac{i_{t}}{k_{t}}-\delta\right)\right]^{-1}
$$

Equation (12) captures the price of a unit of capital and it represents the optimality condition for the capital-producing firms with respect to the choice of $i_{t}{ }^{12}$

\subsection{Equilibrium}

Goods markets clear:

$$
Y_{t}=c_{t}+c_{t}^{\prime}+i_{t}
$$

Financial markets clear: ${ }^{13}$

$$
b_{t}+b_{t}^{\prime}=0
$$

Capital markets clear, so that the stock of capital used by the firms in the economy evolves according to the following equation:

$$
k_{t+1}=\left[\left(\frac{i_{t}}{k_{t}}\right)-\frac{\phi}{2}\left(\frac{i_{t}}{k_{t}}-\delta\right)^{2}\right] k_{t}+(1-\delta) k_{t}
$$

\subsection{Welfare}

To be able to assess the implications of different policies, we numerically evaluate welfare. As discussed in Benigno and Woodford (2008), the two approaches that have been traditionally used for welfare analysis in DSGE models include either characterizing the optimal Ramsey policy, or solving the model

\footnotetext{
${ }^{12}$ This specification of capital production is standard in the literature. See for instance Bernanke et al. (1999) or Unsal (2013).

${ }^{13}$ Because households are savers and entrepreneurs are borrowers, by construction, their assets enter with opposite sign in all the equations.
} 
using a second-order approximation to the structural equations for given policy and then evaluating welfare using this solution. We obtain a solution for the equilibrium implied by a given policy by solving a second-order approximation to the constraints, then evaluating welfare under the policy using this approximate solution, as in Schmitt-Grohe and Uribe (2004). As in Mendicino and Pescatori (2007), we evaluate the welfare of the two types of agents separately. ${ }^{14}$ The individual welfare for savers and borrowers, respectively, as follows: ${ }^{15}$

$$
\begin{gathered}
W_{t} \equiv E_{t} \sum_{m=0}^{\infty} \gamma^{m} \log c_{t+m}, \\
W_{t}^{\prime} \equiv E_{t} \sum_{m=0}^{\infty} \beta^{m}\left[\log c_{t+m}^{\prime}-\frac{\left(l_{t+m}\right)^{\eta}}{\eta}\right],
\end{gathered}
$$

The second-order approximation captures the volatilities of the variables as well the steady-state values of the variables. In the case of the passive policy we also look at the deterministic model to see how the changes in the steady state contribute to total welfare.

To make the results more intuitive, we present welfare changes in terms of consumption equivalents. The consumption equivalent measure defines the fraction of consumption that needs to be given up to equate the welfare under the new policy to the welfare under the baseline case (the policy is not active). A positive value means a welfare gain, hence indicates that the new policy is more desirable from a welfare point of view. The derivation of the welfare benefits in terms of consumption equivalent units is as follows:

$$
\begin{gathered}
C E=\exp \left[(1-\gamma)\left(W^{P}-W^{*}\right)\right]-1, \\
C E^{\prime}=\exp \left[(1-\beta)\left(W^{P}-W^{*}\right)\right]-1,
\end{gathered}
$$

where the superscripts in the welfare values denote the benchmark case when policy is not active

\footnotetext{
${ }^{14}$ See Monacelli (2006) for an example of the Ramsey approach in a model with heterogeneous consumers.

${ }^{15}$ Following Mendicino and Pescatori (2007), we define social welfare as a weighted sum of the individual welfare for the different types of households:

$$
\widehat{W}_{t}=(1-\gamma) W_{t}+(1-\beta) W_{t}^{\prime} .
$$

Each agent's welfare is weighted by her discount factor, respectively, so that the all the groups receive the same level of utility from a constant consumption stream.
} 
and the case in which it is, respectively. ${ }^{16}$

\subsection{Macroprudential Policy Alternatives}

\subsubsection{Active Policy: A Macroprudential Rule}

As an approximation for a realistic active (time-varying) macroprudential policy, we consider a Taylortype rule for collateral requirements. ${ }^{17}$ We can think of regulations on the required collateral as a way to moderate credit booms. When observing a credit boom, increasing collateral requirements, restricts the loans that borrowers can obtain and hence mitigates the credit cycle.

An issue in the implementation of a macroprudential rule would be the availability of relevant and timely data. Therefore, we consider the rule both when there is complete information and when there is incomplete information (noisy/inaccurate and lagged data). The presence of noise and lags in the data may trigger unwarranted or ineffective policy responses which may introduce further volatility to the economy. The evaluation of alternative policy strategies should therefore consider cases where policy reacts to data that is not available in real time (when a policy response must be decided) or it is available with substantial noise.

The rule with complete information Here, we propose the following rule:

$$
z_{t}=z_{S S}\left(\frac{E_{t} b_{t+1}}{b_{S S}}\right)^{\phi_{b}}
$$

where $z_{S S}$ is the steady-state value for the collateral requirement. $\phi_{b} \geq 0$ measures the response of the collateral requirement to expected deviations of credit from its steady state. This kind of rule would be countercyclical, delivering higher requirements during credit booms, therefore restricting the credit in the economy and increasing financial stability. ${ }^{18}$ This policy, as opposed to a passive one, does not imply a change in the steady state of the economy when implemented.

The rule with incomplete information The macroprudential rule with complete information implicitly assumes that the macroprudential regulators observe the current state of the economy promptly

\footnotetext{
${ }^{16}$ We follow Ascari and Ropele (2009).

${ }^{17}$ Here we just consider collateral to granted loans. In reality, in LIDCs, credit booms may be brought by loans to private non-financial companies executing public commands and/or public investment projects. In this paper we abstract from the public sector.

${ }^{18}$ We have experimented with other rules. The collateral requirement responding to the credit-to-GDP delivers very similar results. When it responds to credit growth we encounter indeterminacy issues.
} 
and accurately, and can therefore adjust policy based on this information. However, in many countries, this may not be the case. ${ }^{19}$ As in the monetary policy literature, the availability of relevant and timely data is certainly important for the correct and efficient implementation of rules. ${ }^{20}$

To study the case with incomplete information, we assume that variables are observed both with a lag and with an error. We consider that accurate measures of these variables, which are required for the implementation of an optimal rule, are not known until much later and with noise. We conjecture that (i) the policy-maker observes credit with a lag of four quarters, and (ii) observes $b_{t-4}$ with an error $\left(x_{t}\right)$, so $b_{t-4}=\widetilde{b}_{t-4}+x_{t} .{ }^{21}$ The policy rule then becomes:

$$
z_{t}=z_{S S}\left(\frac{b_{t-4}-x_{t}}{b_{S S}}\right)^{\phi_{b}}
$$

As pointed out by Orphanides (2003), the information problem makes that the policy authority is also reacting to the noise processes. It is obvious that this may introduce undesirable movements in the macroprudential tool and make it less effective.

We assume that the noise follows an $\mathrm{AR}(1)$ process:

$$
x_{t=\varphi} x_{t-1}+v_{t}
$$

where $v_{t}$ is drawn from an independent zero mean normal distribution with variance $\sigma_{v}^{2}$.

\subsubsection{Passive Policy}

For passive macroprudential policy we consider a permanent change in the collateral requirement $(z)$, the macroprudential instrument, as opposed to varying it depending on economic or financial conditions. Such policies are typically advocated in countries in which there are data problems, such as LIDCs, as they are simpler in implementation than a time-varying approach as the data and capacity requirements

\footnotetext{
${ }^{19}$ For instance, in LIDCs, substantial data lags and frequent data revisions are common. The noise in data could reflect statistical inaccuracy or estimation errors - the series that come with a lag or some unobservable theoretical concept (for example natural rate of interest or credit gap) are typically estimated in practice. Additionally, on the conceptual front, defining a steady-state level of credit in LIDCs would also be particularly challenging given the ongoing financial deepening in those countries.

${ }^{20}$ See Orphanides (2003) and Aoki (2003).

${ }^{21}$ We adopt this specification given that data revisions are very common in these countries. Otherwise, we can assume that policy makers observe $b_{t}$ with a noise instead. Our results hold for both specifications. An alternative approach for policy makers would be to estimate $b_{t}$ with learning over time. Given capacity limitations in LIDCs, for simplicity, we rule out this possibility.
} 
could be less demanding. ${ }^{22}$ One implication of using this policy is that, since it represents a permanent change, the economy would reach a different steady state when it is implemented. Increasing collateral requirements means, for example, restricting credit permanently which may be undesirable.

\section{Dynamic Properties}

In this section, we compute impulse responses for an active versus a passive use of macroprudential policy with complete information to understand how dynamics change when macroprudential policies are in place. We present impulse responses for the three most paradigmatic cases: the benchmark case with no macroprudential policies, the active rule with complete information, and the passive policy (corresponding to increasing collateral requirements to the average increase implied by the active rule in order for the two cases to be comparable).

\subsection{Parameter Values}

Table 1 presents a summary of the parameter values used for the benchmark calibration. ${ }^{23}$ The deep parameters are taken from the literature. The value of collateral needed for a loan is $183.2 \%{ }^{24}$ The discount factor for households takes the usual value of 0.99 to reflect an annualized interest rate of approximately $4 \%$. The discount factor for entrepreneurs is slightly lower so that they are impatient agents. ${ }^{25}$ The capital depreciation takes a standard value of $3 \%$. The capital share is about one third. The labor supply value, reflects a labor supply elasticity of one third, in line with the literature. ${ }^{26}$ For our analysis, we will consider demand shocks, that is, an additive shock $\varepsilon_{t}$ in the log-linearized version of the Euler equation for households (equation 9). ${ }^{27}$ We assume that $\log \left(\varepsilon_{t}\right)$ follows an exogenous stochastic

\footnotetext{
${ }^{22}$ A number of LIDCs already set the minimum regulatory capital ratio higher than international standards. For example, a higher regulatory ratio is imposed in Moldova, Uganda and Tanzania (See IMF, 2014,b).

${ }^{23}$ We calibrate the model for a generic country in which the problem of incomplete informtion may be present, with a special focus on LIDCs. Calibration for a specific country may pose difficulties because of data availability and applicability of results to other countries, due to large cross-country heterogeneity.

${ }^{24}$ As a benchmark collateral requirement, we use data from the World Bank Enterprise Survey Data for Sub-Saharan Africa, a region in which the problem of incomplete information is important. This is equivalent to a loan-to-value of 0.54 .

${ }^{25}$ The value of this parameter is not crucial for the results, as long as there is a difference between households and entrepreneurs discount factors that makes the collateral constraint to be binding. We take this value in line with Iacoviello and Minetti (2006), in which it implies a steady state in which the retrun on entrepreneurial investment is $8 \%$.

${ }^{26}$ These values are consistent with Iacoviello and Minetti (2006).

${ }^{27}$ We look at demand-side shocks (fiscal shocks to shocks to external aid, for example) that are prominent for LIDCs. There does not seem to be an established consensus on the benefits of macroprudential policy in the face of supply shocks. For example, as opposed to Kannan et al. (2012) and Angelini et al. (2014), Rubio and Carrasco-Gellago (2014) find the countercyclical use of macroprudential policy effective and welfare improving in response to both demand and supply shocks. The source of the shock matters more if the interactions between monetary and macroprudential policy are studied because supply shocks may decrease inflation while incresing credit gap (or growth), and hence may call for a conflicting monetary and macroprudential responses. We do not focus on these interactions in this paper. We have also experimented
} 


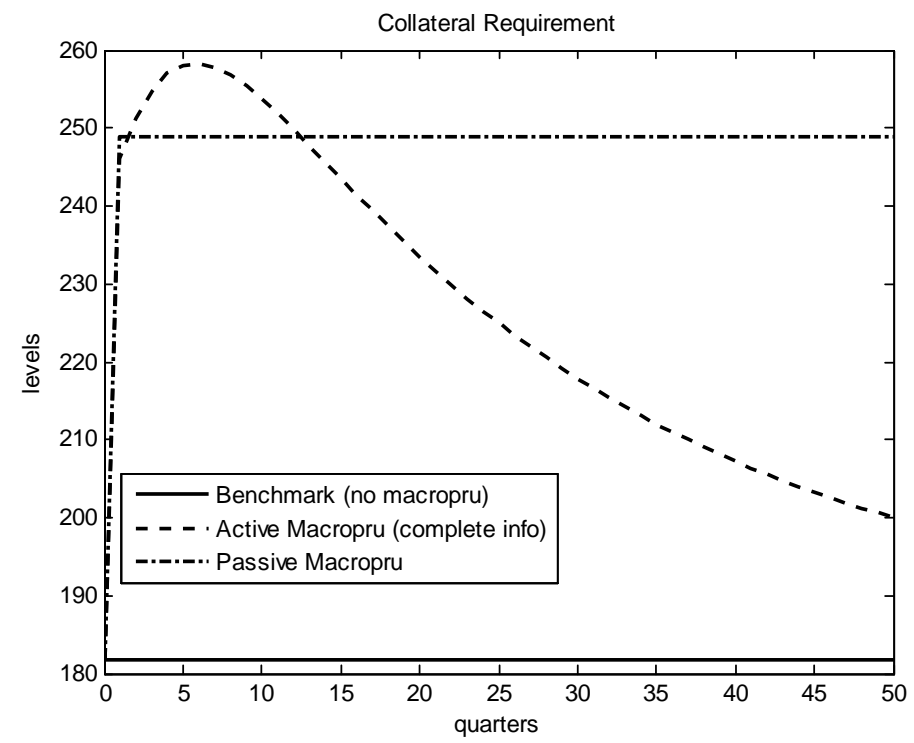

Figure 1: Collateral requirement response (in levels)

stationary AR (1) process around a constant mean. As in the standard framework, this type of shock may reflect changes in tastes or components of demand that do not react to the real interest rate, such as government expenditures. As in Rabanal (2004), the persistence of the demand shock is set to 0.80 .

\begin{tabular}{lll}
\hline \hline \multicolumn{2}{l}{ Table 1: Benchmark Calibration } \\
\hline \hline$\beta$ & Discount Factor Households & 0.99 \\
$\gamma$ & Discount Factor Entrepreneurs & 0.98 \\
$z$ & Collateral Requirement & 183.2 \\
$\delta$ & Capital depreciation & 0.03 \\
$\mu$ & Capital Share & 0.35 \\
$\eta$ & Labor supply & 3 \\
$\rho$ & Shock persistence & 0.8 \\
\hline \hline
\end{tabular}

\subsection{Impulse Responses}

Figure 1 displays the dynamics of the level of the collateral requirement, the instrument of the macroprudential policy-maker, when there is a demand shock. We compare the active rule and a passive approach with the benchmark case, in which there is no macroprudential policy in place. For the active rule, with technology shocks and have found that demand shocks emphasize our results and strengthen the positive effects of macroprudential policies on financial stability. 


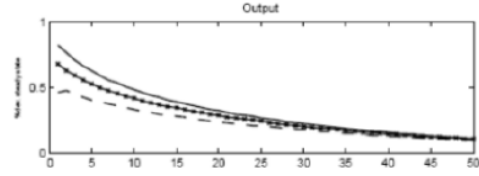

Entropenouirat Consumption

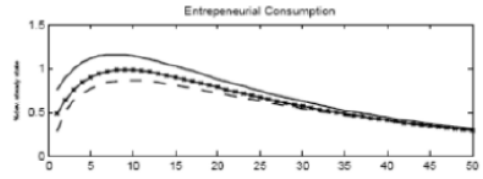

Benown

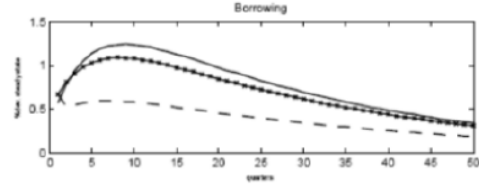

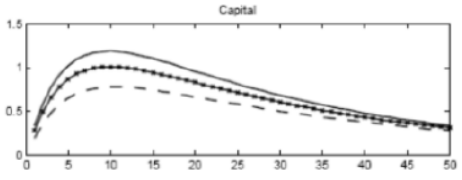
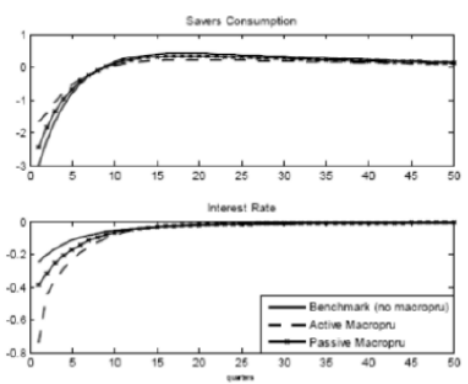

Figure 2: Impulse Responses to a demand Shock. Benchmark (No macropru), active, and passive approaches.

we consider a reaction parameter of 0.5 and complete information. ${ }^{28}$ We calibrate the passive rule in a comparable manner to the active one - we take the average increase of the collateral requirement implied by the active macroprudential rule for the first 20 periods (of the impulse responses) ${ }^{29}$ and approximate a permanent equivalent increase in collateral requirement as a passive macroprudential policy. ${ }^{30}$

For the benchmark case, the collateral requirement remains at its steady-state level (calibrated to 183.2) through the life of the shock. In the case of the active rule, collateral requirements increase and eventually go back to the steady state after a certain number of periods. A positive demand shock generates an extra amount of income in the economy and pushes up investment, consumption, output and borrowing. In order to avoid credit to increase in excess, the macroprudential policy-maker, uses the countercyclical rule and increases collateral requirements. However, as the shock's impact passes away gradually, collateral requirements also return to their initial value.

For the passive implementation of the policy, collateral requirements increase permanently. Note that this policy also achieves the goal of cutting credit but not in a countercyclical and temporary way. Increasing collateral requirements once and for all does not only decrease short-term dynamics of credit but also its steady state. As output in the steady state also decreases, the passive policy entails a long-run output cost.

Figure 2 displays impulse responses for a demand shock for the variables of interest in the model. ${ }^{31}$

\footnotetext{
${ }^{28}$ For presentation purposes, we do not include impulse responses for the incomplete information case, since they are very unstable and make it difficult the comparison. They are available upon request.

${ }^{29}$ We take this choice as a reasonable benchmark but we acknowledge that it is somehow arbitrary.

${ }^{30}$ In the benchmark case, it is an increase in the requirement from 183.2 to 250, approximately.

${ }^{31}$ Note that impulse responses show percent deviations of variables from their steady states. For the case of the active
} 
We can observe from the graph that macroprudential policy mitigates the effects of the shock for aggregate output, especially if the policy is an active one, because of the countercyclicality of the rule. The increases in the collateral requirement that we observed in figure 1 cut down borrowing in both macroprudential cases, more strongly though for the active rule. This dampening in credit makes entrepreneurial consumption not to increase as much as in the benchmark case, mitigating the effects of the initial expansionary shock. Household consumption is the mirror image of entrepreneurial consumption since they now save less than in the benchmark case with no macroprudential policy, responding to the cut in credit. The interest rate decreases more with a macroprudential tool as in our setup, the interest rate is also determined by the collateral requirement. When the requirements increase, the demand for credit decreases and that makes its price decrease as well. ${ }^{32}$

In standard models, with a representative consumer, a demand shock increases interest rates through the Euler equation. The increase in demand makes that households want to consume more today and thus the interest rate increases so that consumers want to postpone consumption and the equilibrium is reached. However, when there are borrowers and savers in the model, there is a different outcome. The demand shock causes a redistribution between borrowers and savers. Borrowers are more impatient than savers and have a larger marginal propensity to consume and thus absorb the shock through the collateral effect. Capital increases and that makes that borrowers increase their borrowing. By construction, savers must increase their saving and this makes interest rates decrease instead of increase through their Euler equation. This effect, becomes smaller when the collateral requirement increases (LTV decreases). In this case, the redistribution due to collateral effects becomes less important and borrowing does not increase as much. Therefore, savers do not save as much and the interest rate does not decrease as much. The evolution of the interest rate does not counteract the effect of the macroprudential policy because with the policy, borrowing is dampened and the stronger the policy in place, through the collateral requirement, the more the interest rate decreases. ${ }^{33}$ In the model, savers' behaviour is fully optimal and their saving pattern follows a standard Euler equation. On the other hand, borrowers are constrained and that leads to a sub-optimal consumption trend, determined by the collateral constraint. Therefore, after the demand shock, savers freely adjust their saving/consumption decision to reach the optimal equilibrium. However, borrowers are not free to do so because the borrowing constraint is imposing a

policy the steady state is not changing with respect to the benchmark, however, for the passive policy, there is a change to a new steady state. We show impulse responses for illustrative purposes but we are aware that they are not fully comparable.

${ }^{32}$ From equations (4) and (6), one can see that the interest rate is inversely related to collateral requirement.

${ }^{33}$ Note that the model does not look at monetary/macroprudential interactions and interest rate in entirely driven by the macroprudential policy as well endogenous saving/borrowing decisions after the shock. 


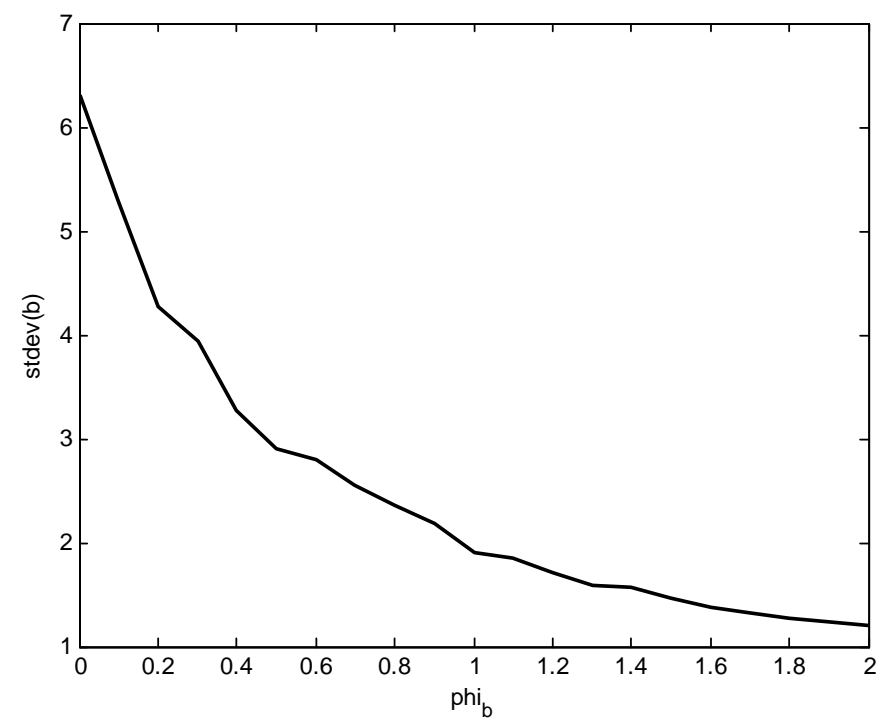

Figure 3: Standard deviation of borrowing for different values of the reaction parameter. Active policy.

limit. This makes "savings prevail over borrowing" in the model. And the stronger the macroprudential policy is the more constrained borrowers are. This means that savings will prevail over borrowing even more.

Overall, we see from the dynamics of the model that the increase in the collateral requirement (that macroprudential policy implies) effectively impacts credit, the goal of the macroprudential policy-maker. The effect is stronger for the active policy - although it mitigates further the effects of the shock than the passive policy, it does not have long run credit and output implications.

\section{Macroeconomic, Financial and Long-run Effects of Macropruden- tial Policy}

\subsection{Active Policy with Complete Information}

Figure 3 displays the financial stability implied by the rule for different values of the parameter $\phi_{b}$. We take the standard deviation of borrowing as a proxy for financial stability. Not surprisingly, the more aggressive the rule is in reacting to deviations of credit from its steady state, the more effective to deliver financial stability is (in the sense of achieving a lower volatility of credit). We see however that the marginal gains in terms of financial stability are decreasing. In fact, for very large values of the reaction parameter, financial stability is still improving but at a very small rate. Given this feature, it 


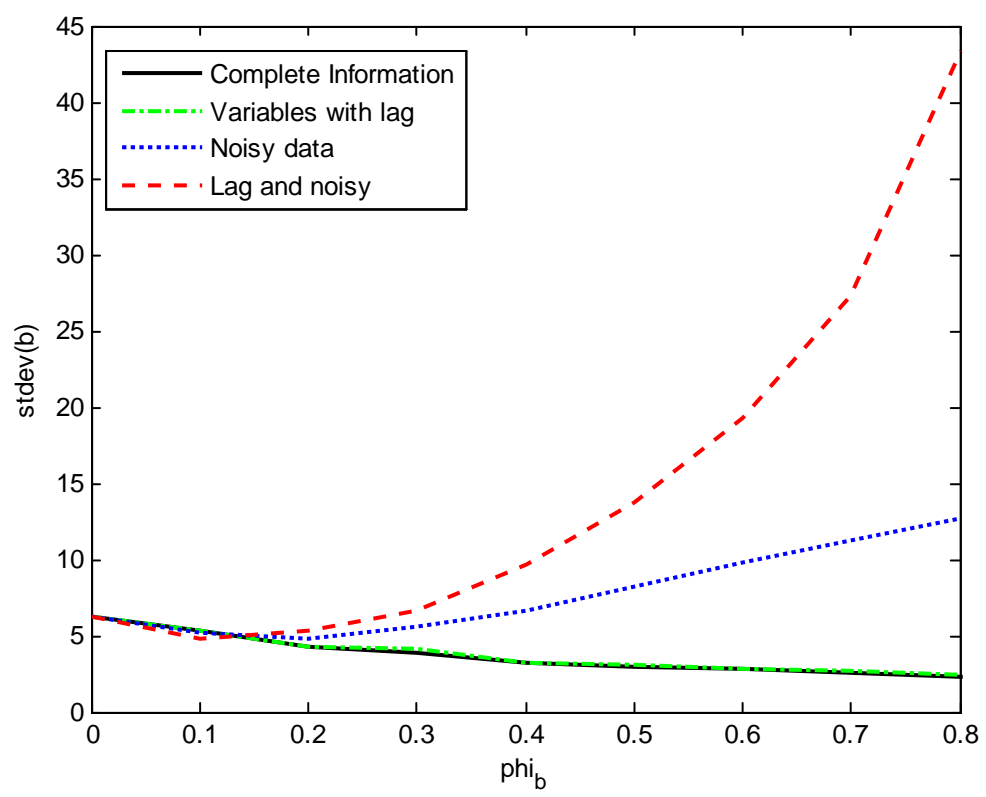

Figure 4: Standard deviation of borrowing for different values of the rule reaction parameter. Active policy.

is not possible to find a value of the reaction parameter for which the variability of credit is minimized such that we could take it as optimal. This finding goes in line with monetary policy studies that try to find an optimal parameter for the inflation coefficient in a Taylor rule. For instance, in SchmittGrohe and Uribe (2007), they find that deviating from the optimal policy rule by setting the inflation coefficient anywhere above unity yields virtually the same level of welfare as the optimal rule. Here, we also find that up to a certain threshold, the improvement in financial stability associated to increasing the aggressiveness of the rule is negligible. ${ }^{34}$ For our analysis, we take a value of 0.5 for this parameter, in order to take a conservative value that is not too far from the monetary policy literature on Taylor rules. ${ }^{35}$ Note again the steady state of output remains at the initial level in this case and therefore, the policy does not imply a long-run output cost. 


\subsection{Active Policy with Incomplete Information}

Figure 4 shows the volatility of credit implied for different values of $\phi_{b}$, the reaction parameter of the macroprudential rule, both when there is complete and incomplete information. For our experiments, we have considered a $1 \%$ shock in the data noise with 0.8 persistence. ${ }^{36}$ For incomplete information, we present three cases: (i) the data comes with a lag, (ii) the data is noisy, and (iii) the data comes with a lag and it is noisy.

We see that for very low values of the reaction parameter, the rule is delivering similar results with complete and incomplete information. This implies that for more cautious implementation of the policy, information problems matter less. Although more aggressive responses are effective under complete information, they are counterproductive under incomplete information as they make credit more volatile.

If variables are observed with a lag, the rule performs only marginally worse than with complete information. When variables are observed with noise, the rule is less effective than with complete information and worsens in fact the stability of the financial system. The combination of lagged and noisy data exacerbates the results - in this case the macroprudential regulator generates more instability compared with the case with no macroprudential policy. However, again, if the policy-maker is more cautious (responds with a low value of the reaction parameter 0.1), the effects of the policy are more limited. ${ }^{37}$

This graph suggests that if there is incomplete information and an active rule is applied, financial stability might get worse than the case with no macroprudential policy, especially if the rule is aggressive. Results are in line with the general finding in the literature on monetary policy under incomplete information that policy performance may change significantly with noisy and lagged data to the extend that the use of an active policy rule can increase rather than decrease instability. Nevertheless, as in the previous case, this policy does not represent a long-run output cost.

In the rest of the paper, incomplete information refers to the case in which the data are noisy and lagged.

\footnotetext{
${ }^{34}$ Schmitt-Grohé and Uribe (2007) find that removing the upper bound on policy parameters optimal policy calls for a much larger inflation coefficient (namely 332), but yields a negligible improvement in welfare. If we check the volatility of borrowing associated with extreme values, we also find negligible improvements. For instance, a coefficient of 100 implies a standard deviation of borrowing of 0.423537 and a coefficient of 1000 a standard deviation of 0.421284 .

${ }^{35}$ The original Taylor estimates for inflation and output response in the Taylor rule are 1.5 and 0.5 respectively. This choice is arbitrary because there is no data to calibrate this parameter. This is why we have introduced Figure 3 so that the reader can see what happens with different values of the parameter but we needed to take a value to make the simulations.

${ }^{36}$ Orphanides (2003) estimates the standard error and persistence of the noise in the data used for US monetary policy. He finds that the standard error is close to $1 \%$ and with high persistence. Given the difficulties of an analogous estimation for LIDCs, we take these values as a benchmark.

${ }^{37}$ In subsequent sections, we will call this case "cautious rule under incomplete information."
} 


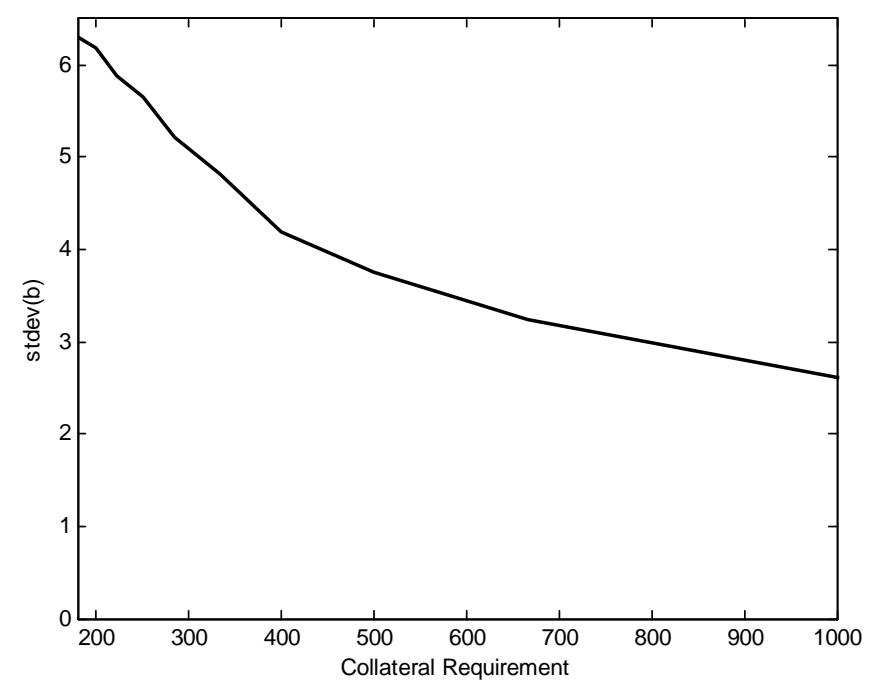

Figure 5: Financial stability implied by increasing collateral requirements. Passive policy.

\subsection{Passive Policy}

Given that the active policy with incomplete information - as commonly observed in LIDCs - may not be desirable, we now turn to an alternative policy. More specifically, in the presence of data and capacity limitations, a simple approach that does not rely too much on data collection or processing may be preferable - that is, a passive policy. As noted above, for passive macroprudential policy rule we consider a permanent change in the collateral requirement. This action may have implications for financial stability since now, the collateral constraint becomes tighter once and for all. On the one hand, this would improve financial stability. However, increasing the collateral requirements permanently implies reducing the steady state of credit and output. Therefore, even though this policy represents a benefit in terms of financial stability, it may also entail a long-term cost in terms of output which is not desirable.

Figure 5 displays the standard deviation of borrowing when collateral requirements are increased with respect to the benchmark initial point $(183.2 \%)$. When collateral requirements increase, the standard deviation of credit decreases - a passive macroprudential policy is able to achieve a higher financial stability.

However, as figure 6 shows, this policy also implies a lower steady-state level of output. Here, we show the output in the steady state that is obtained when increasing the collateral requirement permanently, that is, making the collateral constraint tighter for entrepreneurs. This policy, even though enhancing financial stability, would limit the ability of entrepreneurs to access financial markets and therefore to 




Figure 6: Steady state output implied by increasing collateral requirements. Passive policy.

borrow and produce. This means that the economy has permanently less resources for production and therefore the steady-state output decreases. ${ }^{38}$

This has also very powerful policy implications. If policy-makers are myopic (so that they care more about the short run), they can really hurt the economy by focusing on the financial stability too much under incomplete information. ${ }^{39}$

\section{Macroprudential Policy and Inequality}

The findings from the previous section suggest that, if the financial stability is the only policy objective, the passive policy should be preferred under incomplete information. However, this policy entails an output cost. The natural next step, especially from a point of view of LIDCs income per capita remains low alongside high inequality, is to check how this reduction in output is distributed among entrepreneurs and households. ${ }^{40}$ We base our inequality assessment in terms of consumption, as it is regarded as more consistent with welfare-based considerations than income inequality (see Attanasio and Pistaferri,

\footnotetext{
${ }^{38}$ Note that after a certain level of collateral, the impact of an increase in collateral on the steady state output becomes negligible. Even in lower collateral levels, however, the impact on steady state output seems rather small. If our framework would allow for occupational change - as in Dabla-Norris et al. (2015), for example, such that a credit tightening may push some (productive) entrepreneurs to become workers - the output impact could have been more dramatic. Nevertheless, this result is in line with the literature on advanced and emerging markets that has found that the long-run cost of increases in capital requirements or buffers on credit and output are generally small (See IMF 2014,b).

${ }^{39}$ This could be a reason to argue that macroprudential policy should not be politicized and should be left to an independent institution.

${ }^{40}$ Given the binding collateral constraint, the model allows only for the presence of households with a given financial wealth. However, it is often the case that many households (especially in the bottom deciles of the income distribution) have zero or very low financial wealth and savings.
} 


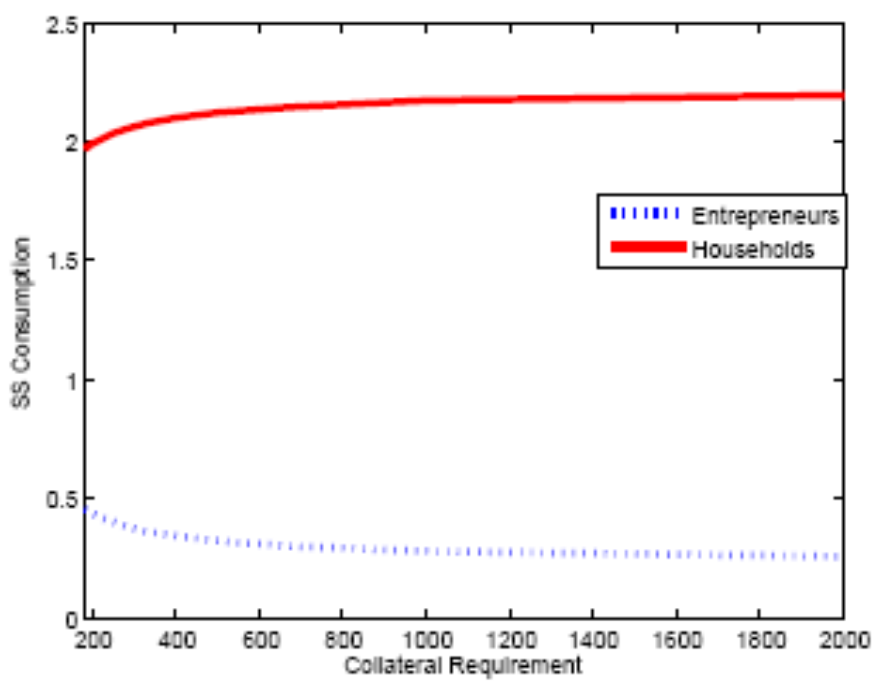

Figure 7: Steady state consumption implied by increasing collateral requirements. Passive policy.

2016). ${ }^{41}$

Figure 7 displays the steady state consumption implied by each level of the collateral requirement. This gives us a sense of the inequality that it is present in the economy. Initially, entrepreneurs have a lower level of consumption in the steady state than households. ${ }^{42}$ However, the gap between the two widens when we apply a passive macroprudential policy - the steady state output loss implied by the policy is not evenly distributed among agents. This means that introducing such a macroprudential tool is increasing the inequality among agents as an undesirable side effect. ${ }^{43}$

A way to numerically assess the level of the implications on inequality is to look at the Gini coefficient which measures the inequality among agents of the levels of income or consumption. A Gini coefficient of zero expresses perfect equality, that is, everyone has the same income. A Gini coefficient of 100 expresses maximal inequality among agents, for instance only one person has all the income or consumption, and all others have none. In our case, we just have two levels of income, low and high, corresponding to the two agents in the model, entrepreneurs and households, respectively. Thus, we can use a simplified calculation of the Gini coefficient as follows: if the high income group is $\mathrm{u} \%$ of the population and earns a fraction $\mathrm{f} \%$ of all income, then the Gini coefficient is $\mathrm{f}-\mathrm{u} .{ }^{44}$ We approximate wealth of each individual

\footnotetext{
${ }^{41}$ As mentioned before, results for inequality are only indicative because the agent heterogeneity in this model only comes from borrowers and savers. Capital producers are not consumers and do not enter the distributional analysis.

${ }^{42}$ Given the difference in discount factors, entrepreneurs represent the low-income agents in the economy. Households are the savers of the economy and they are never in debt.

${ }^{43}$ Given the structure of the model and the difference in discount factors, distributional outcomes do not affect ownership of production factors (capital and labor) and financial wealth.

${ }^{44}$ For example, if the richest represent a $20 \%$ of total population and have $80 \%$ of all income, this would lead to an income Gini coefficient of $60 \%$. Or, an often cited case, if $1 \%$ of all the world's population owns $50 \%$ of all wealth, this means a
} 


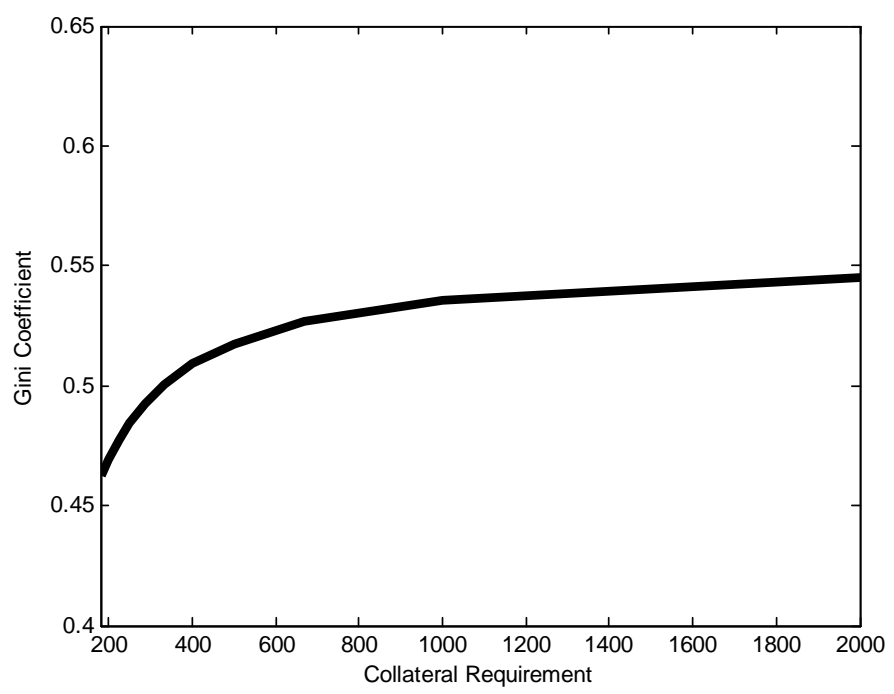

Figure 8: Gini Coefficient implied by increasing collateral requirements. Passive policy.

by their consumption in the steady state.

Figure 8, showing the Gini coefficient implied by each level of collateral requirements, conveys the above results. As collateral requirements increase, the Gini coefficient becomes larger, meaning that inequality goes up. ${ }^{45}$ Therefore, even though using a passive policy may be a priori a good way of introducing macroprudential tools when there is data uncertainty, it has to be taken into account that, as a side-effect, inequality increases permanently. This is not the case though with active policy. As shown in Figure 9, under an active policy, Gini coefficient improves temporarily-given the positive shockbut it goes back to the (same) steady state after a few quarters.

\section{Welfare}

In this section, we present welfare gains associated with changes in policy. Our welfare measure in the stochastic model, as mentioned earlier, would include volatilities and steady-values of consumption (of entrepreneurs and households) and labor (of households). To disentangle the impact of changes in volatilities and steady states, for the passive policy, we also present the results from the deterministic model.

\footnotetext{
wealth Gini coefficient of 49\%. See Litchfield (1999).

${ }^{45}$ We have adjusted the proportion of entrepreneurs (borrowers) to match the initial Gini coefficient close to the average value in LIDCs.
} 


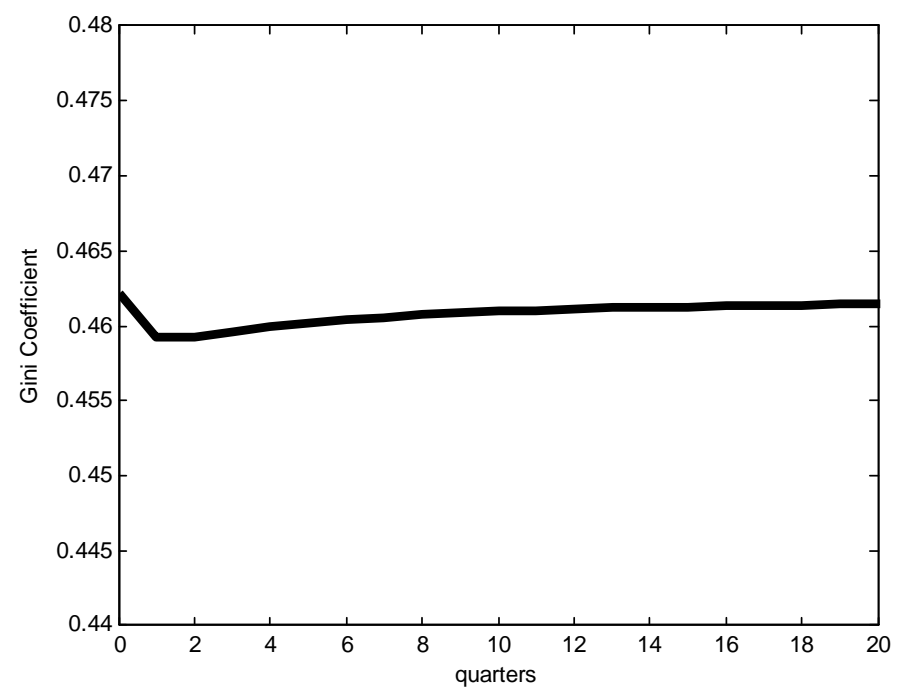

Figure 9: Gini Coefficient. Active policy, complete information.

\subsection{Active Policy with Complete Information}

In terms of welfare, figure 10 displays welfare gains from increasing the aggressiveness of the macroprudential rule. We can observe that entrepreneurs benefit from the macroprudential policy because it delivers a more stable financial system, as also shown in figure 3. Consumption dynamics for both agents are dictated by their respective Euler equations, 4 and 9 . We see from these equations that, whereas consumption smoothing of households relies on interest-rate changes, consumption smoothing for entrepreneurs has an extra term including the Lagrange multiplier of the collateral constraint. That makes that financial variables crucially affect the way entrepreneurs manage to smooth their consumption. In this way, when there is more financial stability, through collateral effects, this is directly translated into more consumption stability and thus this increases welfare. However, although this policy does not entail a long-run output cost, it implies a cost in the short run. The introduction of collateral constraints and the distinction between entrepreneurs/households (borrowers/savers), by construction, always create trade-offs between these two agents in these kind of models, and this is also applied to welfare. Savers, whose consumption is not directly affected financial stability, are worse off because of the cost in terms of output, even if it occurs in the short run. In the aggregate, the economy is better off with the measure. 




Figure 10: Welfare gains for different values of the reaction parameter. Active policy, complete information.

\subsection{Active Policy with Incomplete Information}

Welfare losses from active policy under incomplete information are presented in figure 11. This policy is welfare decreasing, especially for more aggressive rules, confirming the fact that a more financially unstable scenario is created. With this policy we do not even observe a welfare trade-off among agentthe active policy generates more instability in general makes all agents worse off and hence it is not welfare enhancing for anyone in our set up. Implementing an active policy, which is desirable in the case of complete information, is welfare decreasing if taken with the noisy and lagged data.

\subsection{Passive Policy}

The welfare gains implied by the passive policy (Figure 12) are consistent with the above mentioned effects on financial stability and output cost. Increasing collateral requirements implies increasing financial stability and this benefits entrepreneurs. Entrepreneurs welfare directly depends on the volatility of consumption, which in turn, given the collateral constraint, is a direct function of the volatility of borrowing, our proxy for financial stability. The collateral constraint holds with equality in this model and therefore, entrepreneurial consumption is determined by the amount of loans that firms can take. Thus, even though increasing the collateral requirement represents an output cost, as seen in Figure 6, entrepreneurs are better off given the improvement in financial stability (Figure 5). For savers though, this is not the case. Savers are worse-off with the measure because their consumption does not depend 




Figure 11: Welfare gains for different values of the reaction parameter. Active policy, incomplete information.

on financial stability. In the aggregate, however, the economy benefits from the increase in financial stability, mainly coming from the entrepreneurs' side.

In order to disentangle the welfare effects associated with changes in the steady state, we present figure 13. This figure displays the welfare gains for the deterministic case, which represents the change in the steady state due to the policy. ${ }^{46}$ We see that in this case, entrepreneurs are worse off. This is because, as we have seen, when applying the policy, borrowing and output decrease permanently, and this cut is unevenly distributed. Entrepreneurs end up in a steady state with less consumption and households slightly benefit, that is, inequality increases. Therefore, there is a welfare loss for entrepreneurs and a welfare gain for households. In the aggregate, welfare is slightly increasing, reflecting the fact that there is a redistribution of welfare among agents.

\section{$7 \quad$ Policy Comparison}

In this section we present a detailed comparison of different ways of implementing macroprudential policy. As in Angelini et al. (2014) and other studies, the existence of macroprudential regulator is not microfounded in this paper. Rather, we take a positive approach in our evaluation, since as it presents a

\footnotetext{
${ }^{46}$ The passive policy entails a change in the steady state. Therefore, welfare is decomposed between changes in welfare due to i) changes in the steady state and ii) fluctuations with respect to the steady state. The stochastic solution captures these two effects. However, if one would like to disentangle which part of the welfare change is specifically due to the change in regime or steady state, one can calculate the deterministic solution, just due to the change in regime and not to deviations from the steady state.
} 


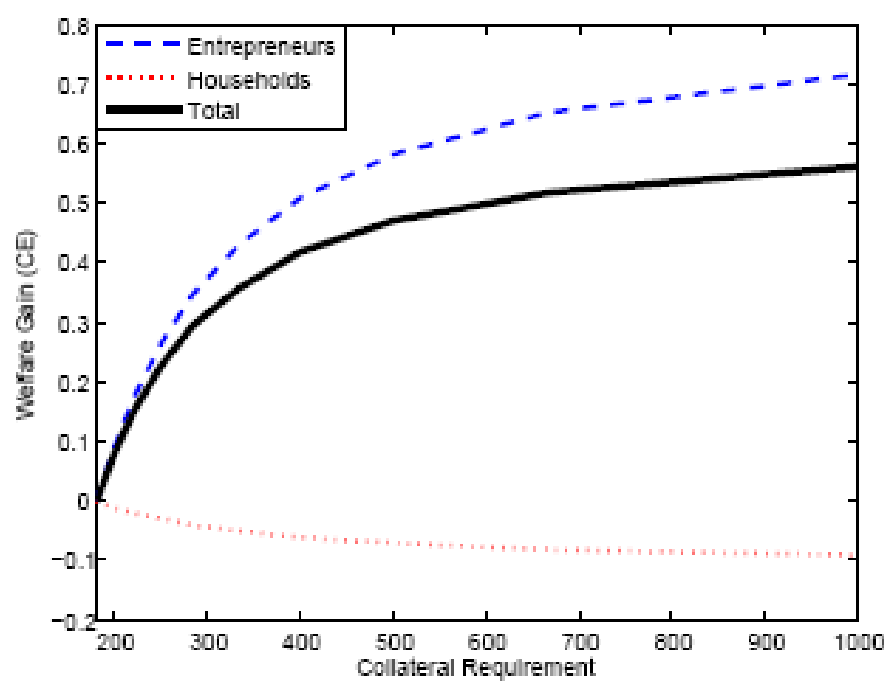

Figure 12: Welfare gains implied by increasing collateral requirement. Stochastic model (Second order approximation). Passive policy.

broader view of the costs and benefits of macroprudential policy which may not be fully captured by the utility function of agents. We take the existence of the collateral constraint and the financial policy as given and compare policies in terms of financial and macroeconomic volatility, as well as inequality, and (utility-based) welfare. ${ }^{47}$ Hence, we consider that the objective of the macroprudential policy-maker is to minimize the volatility in the economy without compromising well-being of economic agents, which we proxy by welfare and inequality. We will rank policies using these criteria.

\subsection{Macroeconomic and Financial Stability, and Long-run Output}

In this subsection we study the implications of the different policies for financial and macroeconomic stability, as well as for the steady state of the economy, both under complete and under incomplete information. We consider that a policy is preferable when it implies higher stability without a macroeconomic cost.

Figure 14 shows how financial stability changes with the collateral requirement for passive policy (the black dashed line). For the active policy we consider both the cases of complete and incomplete information. The active rule with complete information corresponds to the black solid horizontal line. The active rule with incomplete information is represented by the green dashed-dotted horizontal line.

\footnotetext{
${ }^{47}$ This analysis could be comparable to using Taylor curves to rank monetary policies. Taylor curve, or policy frontiers, display the trade-off between inflation and output stabilization, so that a policy that reduces the volatilities of these variables the most is preferred. See for instance Iacoviello (2005), among others, for such evaluations.
} 


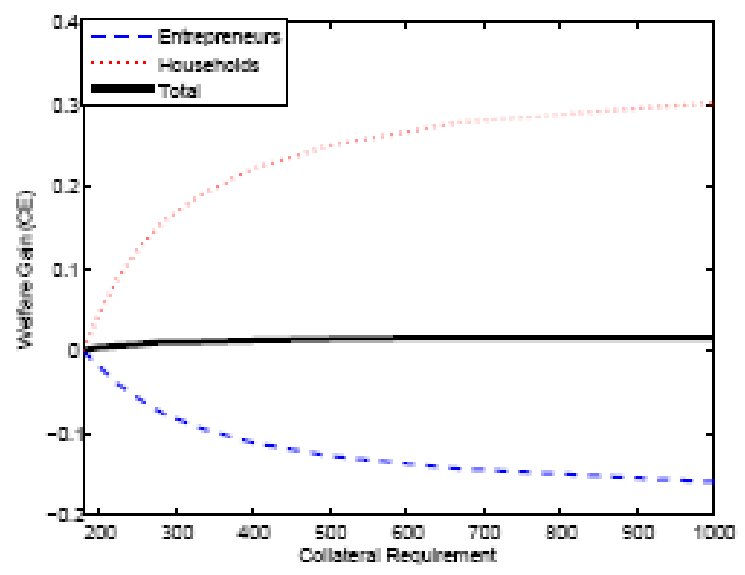

Figure 13: Welfare gains implied by increasing collateral requirement. Deterministic model. Passive policy.

For both rules we present the standard deviation of credit implied by a reaction parameter of 0.5 . The lines are horizontal because financial stability does not depend on the collateral requirement, since at the steady state, it remains constant at the initial calibrated value. We also present in the graph, what we have called the "cautious rule," that is, the rule with incomplete information with a reaction parameter of 0.1 , for which financial instability is not increasing with the policy but its effectiveness is limited. This "cautious rule" corresponds to the red dotted line.

Furthermore, figure 14 also displays the steady-state values of borrowing and output for both the passive and the active rules (blue and black triangles, respectively). In turn, the black and blue circles correspond to the respective steady states of output.

From the graph, we can see that the active rule with complete information is preferred to the passive rule, in the sense that it implies a lower variability of borrowing, for plausible parameters of the collateral requirement. Furthermore, apart from the active rule being preferable from the point of view of financial stability, it does not have associated a long-term steady-state cost in terms of borrowing and output. In order for the passive rule to achieve the same financial stability as the active rule, the collateral requirement would have to go permanently as high as 833 percent, which would imply a steady-state output of 1.74 (an output loss of $5.1 \%)^{48}$. However, if there is incomplete information, things change. The active rule under incomplete information always delivers higher variability of borrowing than a passive approach, even though the latter entails a long-run output cost. For the "cautious rule," the

\footnotetext{
${ }^{48}$ These results are in line with the general consensus that time-varying rules should be preferred to passive ones in advanced economies.
} 


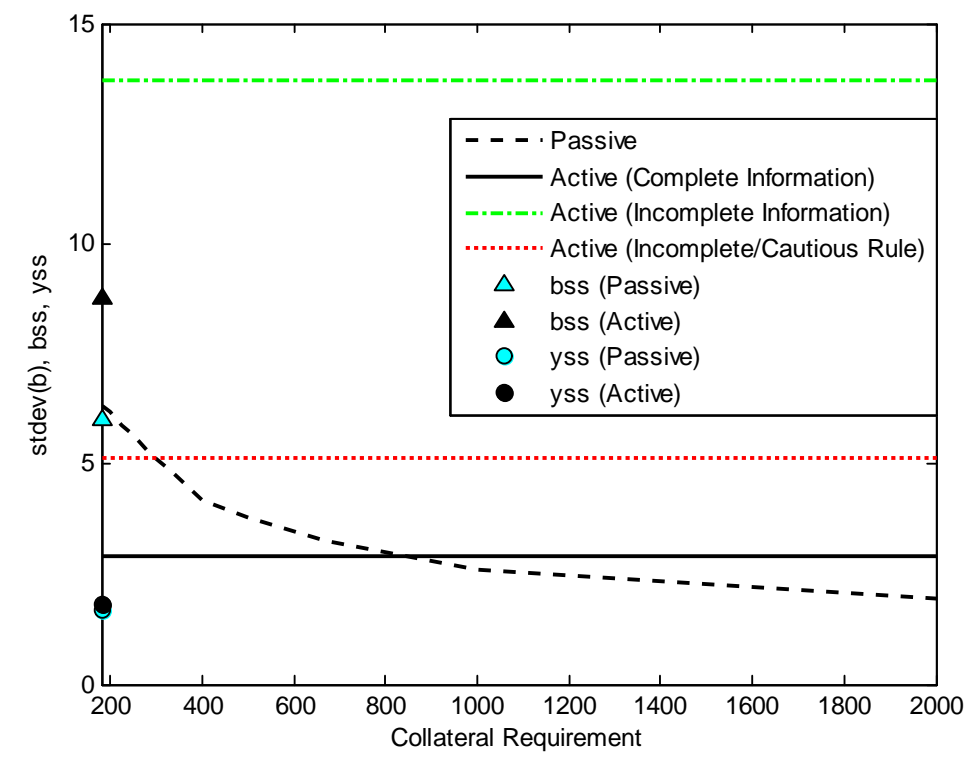

Figure 14: Collateral Requirements and Financial Stability. Active versus Passive.

active rule is preferred to the passive rule up to a value of the collateral requirement of approximately 312 percent. The "cautious rule" under incomplete information is able to deliver higher financial stability than the case with no macroprudential policies but its effectiveness is limited with respect to a more aggressive rule with complete information. ${ }^{49}$

Table 2: Policy Comparison. Volatilities and Steady States

\begin{tabular}{ccccc}
\hline \hline & Benchmark & Active (Complete Inf) & Active (Incomplete Inf) & Passive \\
\hline \hline$\sigma_{b}$ & 6.31 & 2.91 & 13.72 & 5.15 \\
$\sigma_{y}$ & 2.69 & 1.72 & 3.56 & 2.17 \\
$b_{S S}$ & 8.75 & 8.75 & 8.75 & 6.03 \\
$y_{S S}$ & 1.83 & 1.83 & 1.83 & 1.80 \\
\hline \hline
\end{tabular}

Table 2 shows the standard deviations of borrowing and output, as a proxy for financial and macroeconomic stability, for the benchmark (with no macroprudential policy) and for the passive and active rules (both complete and incomplete information). ${ }^{50}$ As for the impulse responses, for the active rule,

\footnotetext{
${ }^{49}$ Quantitative results should be taken with some caution since the rule is not optimally implemented and the value of the noise is not calibrated to a specific case. We focus on the point that with a plausible parameter of the reaction parameter and a large enough shock, results under the complete information case may be reversed in the case of lagged and noisy data.

${ }^{50}$ For robustness, we also check the standard deviation of credit growth. We find that with respect to the benchmark (0.70), both the active rule with complete information and the passive rule deliver a lower standard deviation $(0.67$ and 0.69 , respectively). The active rule with incomplete information delivers the highest volatility (1.73).
} 
we consider a reaction parameter of 0.5 . For the passive rule, we again take the average increase of the collateral requirement implied the macroprudential rule for the first 20 periods (of the impulse responses) and approximate a permanent equivalent increase as a passive macroprudential policy.

Table 2 also presents the steady-state values of borrowing and output, in order to have a sense of the long-run cost that each policy has associated. With complete information, an active rule is preferred to a passive rule in terms of both macroeconomic and financial stability, since the standard deviation of borrowing and output decreases with respect to the benchmark case with no macroprudential policy. Furthermore, the rule does not imply a long-run cost for the economy, since the steady-state values of these two variables remain the same. However, under incomplete information, a passive approach would be more advisable for the objective of attaining a low variability of credit and output, even though it generates a long-run steady-state cost in terms of output and borrowing. ${ }^{51}$

Apart from their impact macroeconomic and financial stability, distributional consequences of alternative policies may be of interest, especially in LIDCs where reducing inequality remains a top policy priority. We take up this issue in the next section.

\subsection{Welfare and Inequality}

Figure 15 compares the total welfare gains (entrepreneurs and households) for the three policies: passive, active with complete information and active with incomplete information. We can observe that the passive policy is preferred to the active one only if collateral requirements increase to more than $400 \%$. However, if there is incomplete information, the policy always generates losses and the passive policy would always be preferable. Nevertheless, as we have seen, this latter policy implies a long-run output cost that is unevenly distributed among agents and increases inequality. This is captured by the welfare calculated for the changes in the steady state (deterministic case).

In Table 3 we present the exact welfare values and inequality implications corresponding to each policy:

\footnotetext{
${ }^{51}$ This result is analogous to the monetary policy literature with noisy data. In this literature, when the economy is difficult to monitor, it is better to adopt more cautious rules (See Orphanides, 2003). Aoiki (2013) finds similar results.
} 


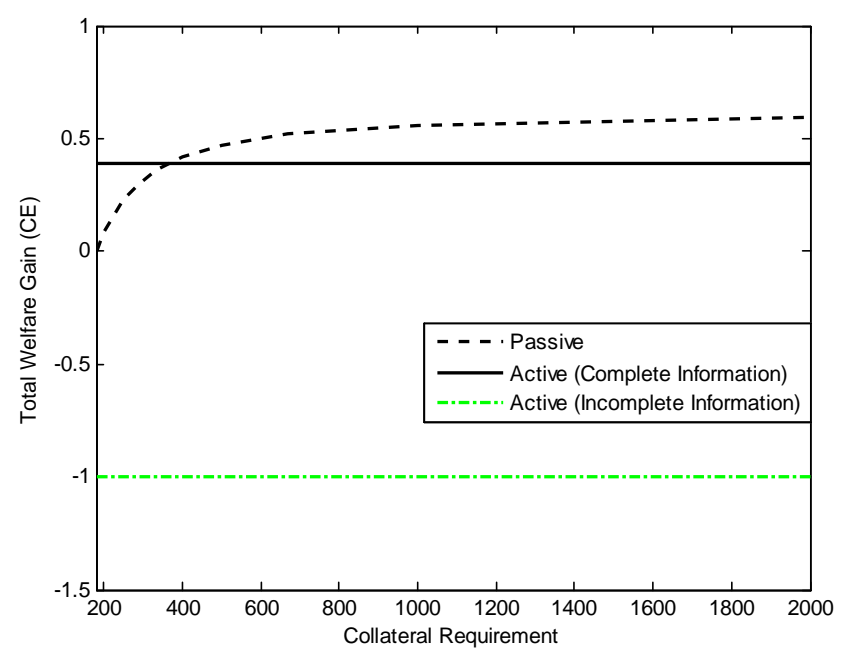

Figure 15: Collateral Requirements and Welfare gains. Active versus Passive.

Table 3: Policy Comparison. Welfare and Inequality

\begin{tabular}{lcccc}
\hline \hline & Benchmark & Active (Complete) & Active (Incomplete) & Passive \\
Welfare gain & - & 0.38 & -0.99 & 0.22 \\
$c_{S S}$ & 0.19 & 0.19 & 0.19 & 0.15 \\
$c_{S S}^{\prime}$ & 6.34 & 6.34 & 6.34 & 6.53 \\
Gini & 0.46 & 0.46 & 0.46 & 0.48 \\
\hline \hline
\end{tabular}

We see that the active policy is preferred to the passive one, in terms of welfare, only under complete information. Otherwise, a passive approach is more advisable but at the cost of generating more inequality in the economy. Indeed, there is a cost in steady-state consumption with passive policy and this is distributed differently among agents. In particular, consumption of entrepreneurs (borrowers), which can be proxied as the poor people of the economy, drops. However, consumption for households goes up, implying an increase in inequality. This result is supported by the Gini coefficient, which is higher for the case of the passive policy.

\section{Concluding Remarks}

In this paper, we use a DSGE model to analyze the alternative ways of implementing macroprudential policy in countries in which incomplete information in data is an important problem. In particular, we focus on the passive versus active implementation of the policy under different information assumptions. In our set-up, passive policy implies increasing collateral requirements permanently. An active policy 
is represented by a countercyclical rule on collateral requirements that respond to expected deviations of credit from its steady state. However, we consider that this indicator may be observed with a noise and/or with a lag.

Results show that macroprudential tools are effective to reduce financial instability, since they lower the volatility of credit. We find that if the macroprudential regulator observes economic indicators timely and without an error, an active time-varying policy is preferred to a passive approach. An active policy, being countercyclical, is more effective to achieve financial stability without incurring in a longrun output cost. A passive policy, although it also improves stability of the financial system, is not as effective as an active one and it implies a permanently lower steady-state output.

However, under incomplete information-noisy and lagged data-, this may not be the case. Under these circumstances, a more cautious (less aggressive) policy or a passive approach may be more advisable for macroeconomic and financial stability, though at the expense of a long-run output cost that is not evenly distributed among agents. We find that a passive policy increases inequality in the economy.

Welfare results are in line with these findings. Macroprudential tools, since they imply a more stable financial system, are welfare enhancing for the constrained group because their consumption volatility directly depends on the variability of borrowing. Looking at the welfare values, we conclude that the active policy is preferred to the passive one, only under complete information. In a situation with incomplete information, commonly observed in LIDCs, passive approaches are preferable but reduce welfare of entrepreneurs due to lower steady-state consumption. ${ }^{52}$

The results from the paper therefore point toward the need for a more careful approach toward the passive macroprudential tools which is usually advocated for LIDCs. Long-run output, inequality and welfare implications of such tools could outweigh their macroeconomic and financial stability benefits. Instead, it is more advisable for countries wit data problems to step up further the efforts to reduce data and capacity problems which, alongside the improvements in the policy framework and implementation, would allow them to better monitor financial systems and be able to use time-varying approaches more effectively. While they make progress on these fronts, less aggressive time-varying macroprudential responses to financial sector developments could be more desirable.

\footnotetext{
${ }^{52}$ A quantitative criterion would certainly help making a final assessment. For future work, it would be nice to rigorously calibrate the model for particular LIDC countries and be able to quantify benefits and costs of the passive approach for each country.
} 


\section{Acknowledgements}

The authors would like to thank Catherine Pattillo, Rupa Duttagupta, Chris Papageorgiou, Prakash Loungani, Matteo Iacoviello, Pau Rabanal, Matteo Ghilardi, Davide Furceri, C. Gueye, David Coady, Maura Francese, R. Bouis, Mourmouras, S. Rafiq, Andy Levine, Galo Nuño, Rafael Portilllo, and Carlos Thomas for their very useful comments. Special thanks to the seminar participants at the IMF, the Bank of England, the University of Konstanz, the Reserve Bank of New Zealand, the Federal Reserve Bank of Cleveland, and the University of Nottingham. We also want to acknowledge the very useful comments received at the NCID Workshop, the Workshop in Development in Economics (La Sapienza, Rome), the SED Conference, the ANAECO Workshop (University of Valencia), the CGBCR Conference (University of Manchester), the "Macroprudential Policies: Experiences and Challenges" workshop (Central Bank of Chile), and the MMF conference on "Macroprudential policies, Inequality, and Financial Inclusion: Redistributive Impacts, and Implications for Financial Stability " at City University in London. The paper was also presented at the ASSA Meeting 2016 session "Macroprudential Policy in Low-Income and Developing Countries." We wish to thank Luca Guerrieri, Federico Signoretti, Markus Kirchner and George Bratsiotis for their very useful discussions. This paper is part of a research project on macroeconomic policy in low-income countries supported by U.K.'s Department for International Development (DFID). This paper should not be reported as representing the views of DFID or the IMF. 


\section{References}

[1] Angelini, P., Neri, S., Panetta, F., (2014), The Interaction between Capital Requirements and Monetary Policy, Journal of Money, Credit and Banking, 46 (6)

[2] Angeloni, I., Faia, E., (2013) 'Capital regulation and monetary policy with fragile banks.' Journal of Monetary Economics 60 (3), pp. 311-324

[3] Aoki, Kosuke (2003), "On the optimal monetary policy response to noisy indicators," Journal of Monetary Economics, Vol. 50, pp. 501-523

[4] Arregui, N., Beneš, J., Krznar, I., Mitra, S, and Oliveira Santos A., (2013), Evaluating the Net Benefits of Macroprudential Policy: A Cookbook, IMF Working Paper 13/167

[5] Ascari, G., Ropele, T., (2009), Disinflation in a DSGE Perspective: Sacrifice Ratio or Welfare Gain Ratio?, Kiel Institute for the World Economy Working Paper, 1499

[6] Attanasio, O., Pistaferri, L., (2016), "Consumption Inequality," Journal of Economic Perspectives, $30(2)$, pp. $1-27$

[7] Baldini, A., Beneš, J., Berg, A., Dao, M. C., and Portillo, R., (2015), "Monetary Policy in Low Income Countries in the Face of the Global Crisis: A Structural Analysis," Pacific Economic Review $20(1)$

[8] Beck, T., Maimbo, S. M., (2013), Financial Sector Development in Africa, The World Bank

[9] Benigno, P., Woodford, M., (2008), Linear-Quadratic Approximation of Optimal Policy Problems, mimeo

[10] Berg, A., Gottschalk, J., Portillo, R., Zanna, L., (2010), The Macroeconomics of Medium-Term Aid Scaling-Up Scenarios, IMF Working Paper 10/160

[11] Bernanke, B. S., Gertler, M., and Gilchrist, S., (1999), "The Financial Accelerator in a Quantitative Business Cycle Framework," Handbook of Macroeconomics, ed. J. B. Taylor and M.Woodford, Vol. 1C, pp. 1341-93

[12] Boehm, C., E., House, C, L., (2014), Optimal Taylor Rules in New Keynesian Models, NBER Working Paper No. 20237 
[13] Dabla-Norris, E., Ji, Y., Towsend, R., and Unsal. D.F., Identifying Constraints to Financial Inclusion and their Impact on GDP and Inequality: A Structural Framework for Policy, IMF Working Paper, $15 / 22$

[14] Gottschalk, R., (2014), Institutional Challenges for Effective Banking Regulation and Supervision in Sub-Saharan Africa, ODI Working Paper 406

[15] Griffith-Jones, S., Gottschalk, R., Spratt, S., (2015), Achieving Financial Stability and Growth in Africa, Routledge book

[16] Gust, C., J., Johannsen, B., K., Lopez-Salido. D., (2015). "Monetary Policy, Incomplete Information, and the Zero Lower Bound," Finance and Economics Discussion Series 2015-099. Washington: Board of Governors of the Federal Reserve System, http://dx.doi.org/10.17016/FEDS.2015.099

[17] Iacoviello, M., (2005), "House Prices, Borrowing Constraints and Monetary Policy in the Business Cycle," American Economic Review, Vol. 95 (3), pp. 739-764.

[18] Iacoviello, M., Minetti, R., (2006), "International Business Cycles with Domestic and Foreign Lenders," Journal of Monetary Economics, Vol. 53, No. 8, pp. 2267-2282

[19] IMF (2014) (a), Proposed New Grouping in WEO Country Classifications: Low-Income Developing Countries, IMF Policy Paper

[20] IMF (2014) (b), Staff Guidance Note on Macroprudential Policy, IMF Staff Papers

[21] IMF (2014),(c), Redistribution, Inequality, and Growth, IMF Staff Discussion Note

[22] Kannan, P., Rabanal, P., Scott, A.M., (2012), Monetary and Macroprudential Policy Rules in a Model with House Price Booms, The B.E. Journal of Macroeconomics, 12 (1)

[23] Kiyotaki, N., Moore, J., (1997), “Credit Cycles.” Journal of Political Economy, 105(2), pp. 211-48

[24] Litchfield, J. (1999)., Inequality: Methods and Tools, The World Bank

[25] Martinez, J., Rabanal, O., Unsal, D.F., "Credit Markets and Macroprudential Policy in Low-Income and Developing Countries", forthcoming IMF working paper.

[26] Masson, P., (2014), Macroprudential Policies, Commodity Prices and Capital Inflows, Bis Paper 76 
[27] Mendicino, C., Pescatori, A., (2007), Credit Frictions, Housing Prices and Optimal Monetary Policy Rules, mimeo

[28] McCallum (2001), "Should Monetary Policy Respond Strongly to Output Gaps?," American Economic Review, 91(2), pp. 258-262

[29] Monacelli, T., (2006), "Optimal Monetary Policy with Collateralized Household Debt and Borrowing Constraint," in conference proceedings "Monetary Policy and Asset Prices" edited by J. Campbell

[30] Orphanides, Attanasios (2003), "Monetary Policy Evaluation With Noisy Information," Journal of Monetary Economics, Vol. 50, No. 3, pp. 605-631

[31] Portillo, R., Unsal, D. F., O'Connell, S., Pattillo, C., "Operational Frameworks, Signaling and the Transmission of Monetary Policy in Low-Income Countries," Monetary Policy in Sub-Saharan Africa, Rafael Portillo and Andrew Berg (eds), forthcoming Oxford University Press.

[32] Rabanal, P., (2004), Monetary Policy Rules and the U.S. Business Cycle: Evidence and Implications, IMF Working Paper WP/04/164

[33] Rubio, M., Carrasco-Gallego, J.A., (2014), "Macroprudential and monetary policies: Implications for financial stability and welfare," Journal of Banking \& Finance, Elsevier, vol. 49 (C), pp. 326-336

[34] Schmitt-Grohe, S., Uribe, M., (2004), "Solving Dynamic General Equilibrium Models Using a Second-Order Approximation to the Policy Function," Journal of Economic Dynamics and Control, $28,755-775$

[35] Schmitt-Grohé, S., Uribe, M., (2007), "Optimal simple and implementable monetary and fiscal rules," Journal of Monetary Economics 54, pp. 702-1725

[36] Taylor, J., Williams, J., (2010), Simple and Robust Rules for Monetary Policy, Federal Reserve Bank of San Francisco Working Paper 2010-10

[37] Unsal, D. F., (2013), "Capital Flows and Financial Stability: Monetary Policy and Macroprudential Responses," International Journal of Central Banking, 9(1), pp. 233-285 